\title{
Management of oral secretions in neurological disease
}

\author{
Alexander J McGeachan, Christopher J McDermott
}

Sheffield Institute for Translational Neuroscience, University of Sheffield, Sheffield, UK

Correspondence to Professor Christopher J McDermott, Reader in Neurology, Sheffield Institute for Translational Neuroscience, University of Sheffield, 385a Glossop Road, Sheffield S10 2HQ, UK; c.j. mcdermott@sheffield.ac.uk

Accepted 29 November 2016 Published Online First 10 February 2017
CrossMark

To cite: McGeachan AJ, McDermott CJ. Pract Neurol 2017;17:96-103.

\begin{abstract}
Sialorrhoea is a common and problematic symptom that arises from a range of neurological conditions associated with bulbar or facial muscle dysfunction. Drooling can significantly affect quality of life due to both physical complications such as oral chapping, and psychological complications such as embarrassment and social isolation. Thicker, tenacious oral and pharyngeal secretions may result from the drying management approach to sialorrhoea. The management of sialorrhoea in neurological diseases depends on the underlying pathology and severity of symptoms. Interventions include anticholinergic drugs, salivary gland-targeted radiotherapy, salivary gland botulinum toxin and surgical approaches. The management of thick secretions involves mainly conservative measures such as pineapple juice as a lytic agent, cough assist, saline nebulisers and suctioning or mucolytic drugs like carbocisteine. Despite a current lack of evidence and variable practice, management of sialorrhoea should form a part of the multidisciplinary approach needed for long-term neurological conditions.
\end{abstract}

\section{WHAT ARE ORAL SECRETIONS?}

Problems due to oral secretions are common and can be distressing in several neurological conditions. Oral secretionrelated symptoms can result from saliva, which may vary in consistency from thin and watery to thick and tenacious, but may also be caused by secretions originating in the nose, throat or lungs. ${ }^{1}$ The picture is often mixed and its management requires a range of treatments. For example, muscle weakness in the face leading to poor lip seal may cause problems with drooling but with evaporation from the mouth leading to thickened saliva from the outset. Alternatively, thick secretions may be the direct result/side effect of the treatments given for managing sialorrhoea. These situations can make management complex, but the aim should be to achieve a balance of symptom control that best improves the quality of life for the patient.

\section{Production of oral secretions}

Saliva is produced by six major salivary glands and several hundred minor salivary glands. The major salivary glands secrete $90 \%$ of the $1.5 \mathrm{~L}$ of saliva produced each day. Healthy people swallow approximately once a minute as a result of saliva pooling, although this varies with its rate of production. ${ }^{2}$ The parotid and submandibular salivary glands are relatively superficial. The submandibular and sublingual salivary glands are primarily responsible for producing background saliva throughout the day, while the parotid glands' primary function is to secrete saliva during periods of olfactory, gustatory and tactile stimulation. ${ }^{3}$ These differences in salivary gland function may be clinically significant, as determining the timing of a patient's saliva problem may allow targeted therapy. Neural stimulation of salivary production is parasympathetic, whereas contraction of salivary duct smooth muscle is stimulated by the sympathetic nervous system. Stimulation of beta-adrenergic receptors is responsible for the production of mucoid secretions. Oral secretions have several important physiological functions. Saliva protects oral tissue, lubricates food for swallowing and contributes to maintaining good dental health. Saliva and mucoid secretions form a vital part of a patient's barrier immune system. ${ }^{4}$

\section{Sialorrhoea and its symptoms}

Sialorrhoea is an inconsistently used term most commonly describing excessive serous saliva in the mouth that can result from hypersecretion of saliva, anatomical abnormalities or facial-bulbar weakness. 
In neurological conditions, this excessive saliva results from weakness or poor coordination of bulbar or facial musculature. This leads to ineffective swallowing mechanics, reduced swallowing frequency, poor lip seal and ineffective saliva control, but not excessive production of saliva. ${ }^{1} \quad{ }^{5} \quad 6 \quad$ Sialorrhoea commonly affects adults with various neurological conditions including stroke; neuromuscular diseases such as amyotrophic lateral sclerosis/motor neurone disease and neurodegenerative diseases such as Parkinson's disease, multiple system atrophy, progressive supranuclear palsy and dementia with Lewy bodies. Although it is often stated that autonomic dysfunction in Parkinson's disease causes hypersalivation contributing to the sialorrhoea, studies into salivary production in this condition show reduced or normal salivation compared with controls. ${ }^{5} 7$

Estimates of the prevalence of sialorrhoea in those neurological conditions most commonly associated with this symptoms are as follows: Parkinson's disease $10 \%-84 \% ;{ }^{5}$ motor neurone disease $20 \%-40 \%{ }^{8}$ and cerebral palsy 20\%-58\%. ${ }^{9} 10$

Physical consequences of sialorrhoea include excoriation of the skin around the mouth, speech and sleep disturbance, dehydration and increasing fatigue. These physical problems are also associated with psychosocial symptoms such as embarrassment and social withdrawal. ${ }^{11}$ In many patients with neurological disease these symptoms will be accentuated by muscle weakness or dystonia in the neck, trunk or limbs causing a flexed posture and/or difficulties maintaining oral hygiene. Saliva may also pool at the back of the throat, causing coughing and a higher risk of aspiration. ${ }^{12}$ There are reports of pooling of saliva affecting patient's ability to use non-invasive ventilation, which in neuromuscular diseases-particularly motor neurone disease-is an intervention that improves the quality of life and survival. ${ }^{13}$

\section{Tenacious saliva and thick secretions}

The burden of problematic thickened secretions is also poorly defined. It is important to recognise that patients with sialorrhoea may also have thickened secretions collecting in their mouth and throat, often resulting from treatments for sialorrhoea. Thick secretions can lead to chewing and swallowing problems and can also impact on the tolerance of non-invasive ventilation. ${ }^{14} 15$

\section{ASSESSMENT OF ORAL SECRETIONS}

Areas that are important to clarify include:

1. Evaluating the type of secretions the patient is suffering from, that is, sialorrhoea, thick secretions or both; consider the impact of saliva collecting at the back of the oral cavity.
2. The cause of the symptoms, that is, does the patient have dysphagia, poor lip seal, learning difficulties, and is there any possibility that the patient has anatomical abnormalities or salivary hypersecretion.

3. The timing of the problem. Although unstudied, physiology suggests that if a patient has symptoms throughout the day, then targeted therapies such as botulinum toxin and radiotherapy may need to include the submandibular gland, while if they have symptoms mainly when eating or drinking, treatment of the parotid glands may be more successful.

4. Whether secretions are impacting on the ability to use non-invasive ventilation.

5. What steps have already been taking to try and manage the problem and what other medications they take.

There are many proposed methods to evaluate oral secretions systematically. Quantitative measures such as weighing cotton rolls and collection cups are largely impractical but can assess reductions in salivary flow. However, such assessments correlate poorly with subjective symptom improvement and so are of little use in clinical practice. ${ }^{16}$ There are several patient reported and observer reported symptom rating scales. Most of these focus on drooling, but some also include questions assessing other sialorrhoea-related symptoms, subjective impact on other aspects of life and concurrent thick secretion problems. ${ }^{17-19}$ This lack of an effective or uniform outcome measure for evaluating oral secretion problems is a significant barrier to the generation of good evidence.

\section{MANAGING SIALORRHOEA}

A multidisciplinary approach should be taken; conservative measures such as suction, drug therapy most commonly with anticholinergics, repeated botulinum toxin injections and radiotherapy and surgical interventions have all been used to manage sialorrhoea (table 1). No one treatment modality will succeed for every patient and so a combination of approaches is required, undertaken in a stepwise fashion (figure 1)..$^{5112021}$ Moreover, patients with different underlying diseases may benefit from different interventions. Notably, sialorrhoea in patients with Parkinson's disease usually occurs during 'off' periods of symptom control. Consequently the most important first step is to optimise dopaminergic therapy to optimise swallowing function. ${ }^{5}$

\section{Conservative measures}

Although there is little evidence confirming their effect, there are various available conservative measures for managing sialorrhoea and associated symptoms. The appropriate use of these conservative managements will vary between patients. 
Table 1 Summary of treatment options

\begin{tabular}{|c|c|c|c|}
\hline Type of therapy & Benefits of this approach & Side effects & Additional information \\
\hline $\begin{array}{l}\text { Conservative } \\
\text { measures }\end{array}$ & $\begin{array}{l}\text { Largely cheap } \\
\text { Simple } \\
\text { Minimal side effects }\end{array}$ & Few & Consider these in all patients \\
\hline Anticholinergics & $\begin{array}{l}\text { Easy to prescribe } \\
\text { Cheap }\end{array}$ & $\begin{array}{l}\text { Urinary retention, blurred vision, } \\
\text { confusion }\end{array}$ & Caution in myasthenia gravis-related drooling \\
\hline Botulinum toxin & Targeted therapy & Excessively dry mouth & Concerns over effects on bulbar function \\
\hline Radiotherapy & Targeted therapy & $\begin{array}{l}\text { Excessively dry mouth } \\
\text { Risk of malignancy }\end{array}$ & $\begin{array}{l}\text { Effects (including adverse effects) last from } \\
\text { months to years }\end{array}$ \\
\hline Surgery & $\begin{array}{l}\text { Long-term symptom relief if } \\
\text { effective }\end{array}$ & $\begin{array}{l}\text { Generic surgical and anaesthetic } \\
\text { risks } \\
\text { Retention cysts }\end{array}$ & $\begin{array}{l}\text { Irreversible } \\
\text { Patients may be too frail to tolerate }\end{array}$ \\
\hline
\end{tabular}

Neck collars and head-back wheelchairs are useful devices to improve positioning and counteract a flexed posture. This simple measure is likely to improve patients' comfort and self-image. Speech therapy should be involved early, aiming to maximise the patient's swallowing function and lip seal. Oral prostheses, trialled in neurologically impaired patients to improve lip seal, improve quality of life. ${ }^{22}$ For patients with Parkinson's disease, reduced oral sensation or cerebral pathology, swallow reminders may help. ${ }^{6}$
Several oro-rehabilitation approaches have also been used in neurologically and cognitively impaired children with success. These include oromotor therapy, biofeedback or behavioural interventions. ${ }^{23}$

Portable suction devices can be considered in patients with treatment-resistant symptoms, particularly if they have pooling of saliva in the throat. While these devices are portable they are not necessarily discrete and patients may find using them embarrassing (figure 2).

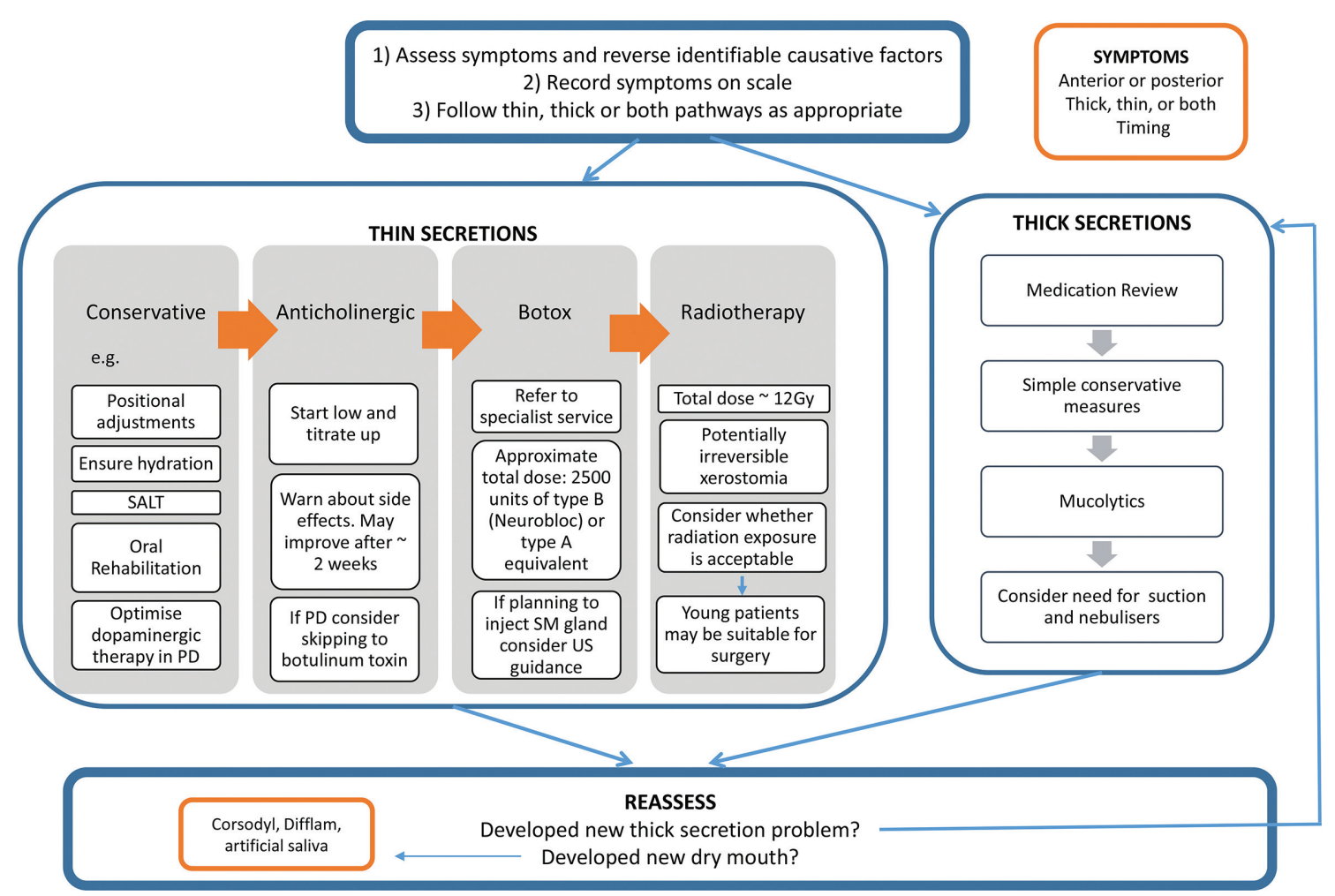

Figure 1 A suggested generic management approach to a patient with symptoms relating to oral secretions. This management approach is derived from expert clinician experience. PD, Parkinson's disease; SM, submandibular. 


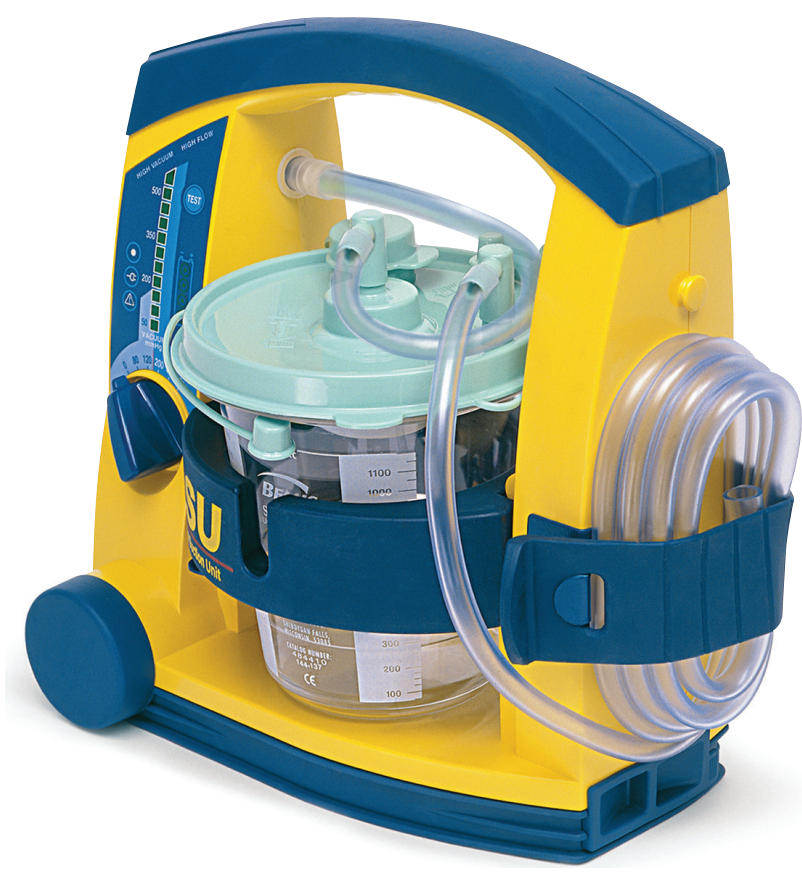

Figure 2 Portable suction unit.

\section{Anticholinergics}

Anticholinergics are a group of drugs that inhibit the action of the neurotransmitter acetylcholine at muscarinic receptors, thus reducing saliva production. Care must be taken when using anticholinergics not to cause an excessively dry mouth. This may be more distressing for the patient than their original problem and can contribute to poor oral hygeine. ${ }^{24} 25$ There are various anticholinergics and drugs with anticholinergic effects that are used to manage sialorrhoea, including hyoscine hydrobromide, atropine, glycopyrrolate, tropicaimide, hyoscyamine sulfate and the tricyclic antidepressant amitriptyline (table 2). ${ }^{5} 2026$ However, there is only limited evidence supporting these drugs as effective interventions, with only a few studies carried out across a range of diseases. ${ }^{27}$

Unfortunately, these medications are not specific to the muscarinic receptors of the salivary glands. ${ }^{25}$ Patients using these medications for sialorrhoea management risk unwanted effects in other organ tissues. These effects include urinary retention, constipation, increased intraocular pressure, cessation of perspiration with increased body temperature and double vision. Moreover, anticholinergics can affect the central nervous system causing adverse effects such as confusion, disorientation, memory problems, sedation and nausea, which can often be intolerable, especially in the elderly. $^{24} 25$ The topically applied hyoscine patch can also cause skin irritation that is often severe enough that it has to be stopped. ${ }^{28}$

\section{Parkinson's disease and anticholinergics}

It is important to note that there are a set of circumstances relating to Parkinson's disease that require significant caution when prescribing anticholinergics. First, many patients with Parkinson's disease have autonomic dysfunction and so are extremely sensitive to the unwanted effects of these drugs on other organs, for example, the bladder. Moreover, patients with Parkinson's disease-particularly in its later stages-suffer from cognitive impairment and so may be more likely to become confused when using these drugs. There is also a concern that anticholinergics can cause taurelated pathology and increased Alzheimer's pathology in patients with Parkinson's disease. ${ }^{29}$

Glycopyrronium has a structure which means it does not cross the blood-brain barrier as readily; its use as an oral solution has been trialled in 23 patients with Parkinson's disease, showing symptom improvement and a good side effect profile. ${ }^{30}$ We need more

Table 2 Example of anticholinergics used to treat sialorrhoea

\begin{tabular}{|c|c|c|c|}
\hline $\begin{array}{l}\text { Name of } \\
\text { anticholinergic }\end{array}$ & Preparation & Dose & Specific characteristics and cautions \\
\hline $\begin{array}{l}\text { Hyoscine } \\
\text { hydrobromide }\end{array}$ & Transdermal patch & $\begin{array}{l}0.5 \mathrm{mg} \text { patch per } 72 \\
\text { hours }\end{array}$ & $\begin{array}{l}\text { Associated with a skin reaction at the site of the patch. Frequently } \\
\text { altering the patch site and using topically applied steroid may improve } \\
\text { tolerance. }{ }^{28}\end{array}$ \\
\hline Glycopyrronium & $\begin{array}{l}\text { Tablet Oral solution } \\
\text { (trialled in children) }\end{array}$ & $\begin{array}{l}1-2 \mathrm{mg} \text { three times } \\
\text { daily }\end{array}$ & $\begin{array}{l}\text { Glycopyrronium has a quaternary ammonium structure that renders it less } \\
\text { permeable to the blood-brain barrier. Consequently, it is likely to be less } \\
\text { associated with CNS side effects. }{ }^{30} 39-41\end{array}$ \\
\hline Amitriptyline & Tablet & $10-50 \mathrm{mg}$ at bedtime & $\begin{array}{l}\text { Amitriptyline has several other effects that may be exploited. These } \\
\text { include sedative and antidepressant effects. However, the antidepressant } \\
\text { dose is much higher than that typically used to treat sialorrhoea. }{ }^{42}\end{array}$ \\
\hline Atropine & $0.5 \%$ Eye drops & $\begin{array}{l}1-2 \text { drops sublingually } \\
\text { four to six times daily }\end{array}$ & $\begin{array}{l}\text { Can be useful if related to meals as it can be administered when the } \\
\text { problem occurs. }{ }^{4344}\end{array}$ \\
\hline
\end{tabular}

CNS, central nervous system. 
research to determine the appropriateness of anticholinergics in this population and for the reasons outlined above, early consideration of botulinum toxin injections may be appropriate.

\section{Dosing regimens}

The optimal doses and delivery mechanisms for these treatments have not been identified; however with a high risk of side effects, the approach should be to start at a low dose and titrate up as required and tolerated.

\section{Botulinum toxin}

Botulinum toxin is a neurotoxin produced by the bacterium Clostridium botulinum. It has been used since the $1980 \mathrm{~s}$ to treat conditions such as strabismus and dystonia. There are seven types (A-G) that work by penetrating the axon terminals and degrading synaptosome associated protein (SNAP)25 proteins, preventing neurosecretory vesicles fusion with the nerve synapse plasma membrane. ${ }^{31}$

${ }^{32}$ Both botulinum toxin $\mathrm{A}$ and $\mathrm{B}$ have been used to manage sialorrhoea (table 3 ). ${ }^{33}$

\section{Radiotherapy}

External beam radiotherapy using photons or electrons is an alternative method for controlling sialorrhoea. It is usually used following the failure to respond to or tolerate treatment with anticholinergic drugs and botulinum toxin. There are several retrospective and prospective studies, carried out in patients with Parkinson's disease and motor neurone disease, reporting objective reductions in saliva production and improvements in patient symptoms. ${ }^{34}$ While these studies did not include control groups, the same patients had previously failed to achieve symptom control with other available treatments for sialorrhoea. As with botulinum toxin injections, there is no consensus about the optimal dosing regimen for salivary gland irradiation to treat sialorrhoea. Most commonly used regimens target both submandibular glands and the caudal two-thirds of both parotid glands. Studies to date have used a range of doses, with a median dose per fraction of 5 Gy (0.83-8 Gy) and a mean total dose of 12 Gy (3$48 \mathrm{~Gy})$. The length of the effect of radiotherapy is variable and was reported to last for several months to 5 years, with around half of patients still experiencing effects at 6 months.

Radiotoxicity can occur resulting in an overly dry mouth with more viscous saliva, facial erythema, pain and nausea. ${ }^{34}$ These effects are usually short lived and the risk of their development is likely to be reduced with new techniques, such as CT mapping which

Table 3 A summary of botulinum toxin for the management of sialorrhoea

\begin{tabular}{|c|c|c|}
\hline \multirow[t]{2}{*}{ Toxin types } & \multicolumn{2}{|c|}{$\begin{array}{l}\text { Due to multiple type A botulinum toxin subtypes, it is difficult to make direct comparisons between the effects } \\
\text { of type } A \text { and type B toxins. When treating sialorrhoea, the comparative dose of botulinum toxin } A \text { (Botox) to } \\
\text { botulinum toxin B is approximately } 1: 10 .{ }^{45}\end{array}$} \\
\hline & $\begin{array}{l}\text { Type A } \\
\text { There are subtypes of type A botulinum toxin, two of which } \\
\text { (Botox and Dysport) are commonly used to treat } \\
\text { sialorrhoea. These subtypes have different biological } \\
\text { activities; thus, dose adjustments must be made } \\
\text { accordingly (Botox 1:3 Dysport). }\end{array}$ & $\begin{array}{l}\text { Type B (NeuroBloc) } \\
\text { Has a greater propensity for autonomic effects. }{ }^{46} \\
\text { Has a higher immunogenicity and so repeated use may have } \\
\text { a greater risk of antibody-induced failure. }{ }^{47} 48\end{array}$ \\
\hline Dosing & \multicolumn{2}{|c|}{$\begin{array}{l}\text { Commonly used doses in trials to date: } 100 \mathrm{MU} \text { of Botox, } 250 \mathrm{MU} \text { of Dysport, } 2500 \mathrm{MU} \text { of NeuroBloc. } \\
\text { Doses should be divided between the submandibular and parotid glands, with the parotid receiving a greater fraction of the } \\
\text { total dose. }\end{array}$} \\
\hline Delivery & $\begin{array}{l}\text { US guidance } \\
\text { Confirms accurate delivery of the toxin }\end{array}$ & $\begin{array}{l}\text { Landmark guided } \\
\text { Practical and largely considered safe (figure 3) }\end{array}$ \\
\hline $\begin{array}{l}\text { Outcomes of } \\
\text { treatment with } \\
\text { botulinum toxin }\end{array}$ & $\begin{array}{l}\text { Advantages }{ }^{50} \\
\text { Meta-analysis data supporting its clinical efficacy } \\
\text { Effective in patients with symptoms resistant to medications } \\
\text { Effects last for } 3-6 \text { months } \\
\text { Fewer side effects than anticholinergic medication } \\
\text { - Minimally invasive } \\
\text { May decrease risk of aspiration pneumonia in } \\
\text { neurologically impaired children. }{ }^{51}\end{array}$ & $\begin{array}{l}\text { Disadvantages } \\
\text { Common adverse effects: xerostomia, thickened bronchial } \\
\text { secretions and viscous saliva, difficulty chewing and pain at } \\
\text { the site of injection. Reverse slowly as toxin effect wears } \\
\text { off. }{ }^{52} \\
\text { Dysphagia is a rare side effect. }{ }^{53} \\
\text { Repeat injections may result in antibody formation and } \\
\text { fading efficacy. }{ }^{49}\end{array}$ \\
\hline $\begin{array}{l}\text { Group } \\
\text { characteristics }\end{array}$ & \multicolumn{2}{|c|}{$\begin{array}{l}\text { Patients with motor neurone disease may be more prone to adverse effects and shorter benefit duration compared with those } \\
\text { with Parkinson's disease. } \\
\text { Old age may be associated with longer benefit duration. }{ }^{53}\end{array}$} \\
\hline
\end{tabular}

MU, mouse units; US, ultrasound. 


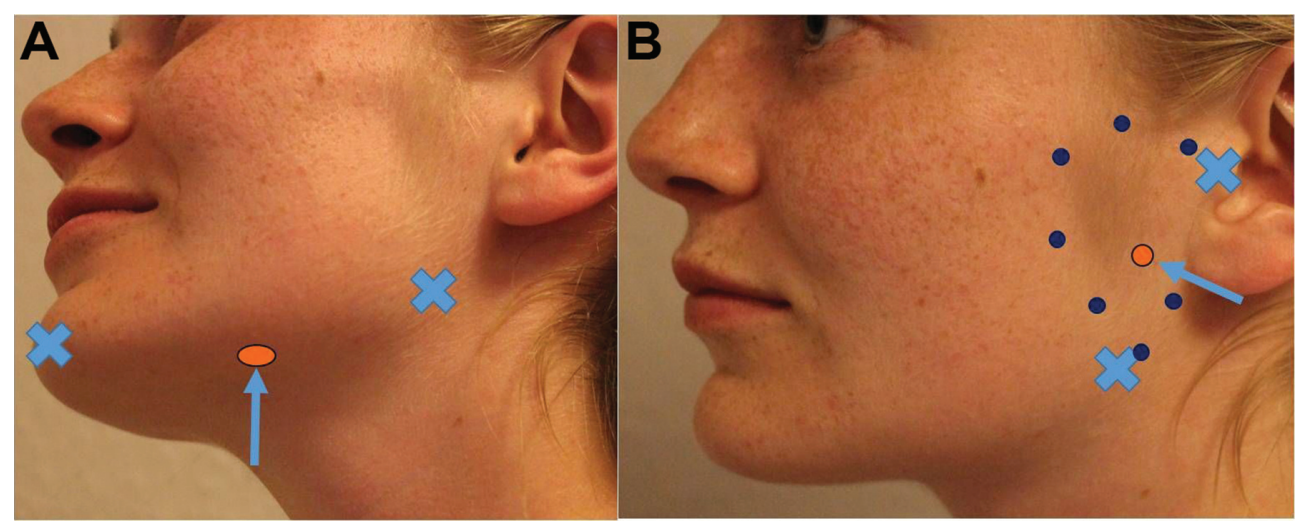

Figure 3 Delivering botulinum toxin injections by landmark guidance. (A) Locating the submandibular gland: Find the midpoint between the angle of the mandible and the tip of the chin. Inject 1 finger breadth medial to the inferior surface of the mandible at this point. Direct needle straight upwards, staying as close to the medial surface of the mandible as possible. (B) Locating the parotid gland: Find the midpoint on the line connecting the tragus to the angle of the mandible, approximately the site of the ear lobe. Deliver injection $1 \mathrm{~cm}$ anterior to this site. Source: Adapted the image from Srivanitchapoom et al. ${ }^{4}$

allows for highly localised therapy. ${ }^{35}$ Because many of the patients with neurological disease have a short life expectancy, there is less concern about malignancy; however, in those with longer life expectancy this may be an unnecessary risk.

\section{Surgical options}

There are some effective surgical interventions for sialorrhoea. Options include removing the submandibular or parotids salivary glands, relocating or ligating the submandibular and/or parotid duct and transtympanic neurectomy. ${ }^{36}$ These surgical interventions have most commonly been used in neurologically impaired children with symptoms resistant to medication and botulinum toxin. Using surgery to manage sialorrhoea in older patients is rare and would only be considered after less-invasive approaches have failed.

Meta-analysis of surgical options suggests that bilateral submandibular duct rerouting, bilateral submandibular gland excision with bilateral parotid duct rerouting and bilateral submandibular gland excision with bilateral parotid duct ligation appear to be of similar efficacy. ${ }^{36}$ While potentially less effective, four-duct ligation offers a simple, quick and safe procedure that may improve symptoms. ${ }^{37}$

Many patients with motor neurone disease, Parkinson's disease and other neuromuscular and neurodegenerative disorders do not have the functional reserve to tolerate surgical intervention. Additionally, life expectancy is often short and so there is less need for interventions that will work for many years.

\section{MANAGEMENT OF THICK SECRETIONS}

Symptoms related to thickened secretions often are difficult to manage, with the available treatment options more limited than those for sialorrhoea. If a patient is distressed by thickened secretions-from treating sialorrhoea-then titrating down to the smallest effective dose can be helpful. Discussions with the patients and carers about which of these opposing secretion problems is more troublesome will help to achieve the best balance for the patient.

There are a number of options for alleviating the discomfort associated with thickened saliva, many of which are conservative. Simple approaches include checking the patient's fluid intake, thinning secretions with juices and ice cubes-grape, apple, pineapple or papaya-or frequent swabbing of the mouth. Using a mouthwash of one teaspoon bicarbonate of soda or one teaspoon salt in a glass of water after meals can also help. Mucolytic agents such as $\mathrm{N}$-acetylcysteine and carbocisteine are

\section{Key points}

Sialorrhoea is common in several neurological conditions and the physical complications of drooling such as perioral chapping can lead to embarrassment and social isolation that significantly affect the quality of life.

- Sialorrhoea can be associated with problems with thicker, tenacious oral secretions; when this is the result of the drying management approach to sialorrhoea, a balanced approach is needed.

- Sialorrhoea can be managed using various treatments including anticholinergic drugs, salivary gland-targeted radiotherapy, salivary gland botulinum toxin and surgical approaches, which should be used in a stepwise fashion.

- There is currently a little evidence to direct optimal secretion management, but effective long-term management usually requires a multidisciplinary team approach and a combination of treatments. 
effective and commonly used. ${ }^{38}$ A pilot study in 1996 investigated the use of beta-blockers in managing thick mucoid saliva with promising results, but to date there appears not to have been any confirmatory studies. ${ }^{1}$

In patients with more problematic symptoms, other measures include nebulised saline to loosen and thin secretions or using suction pumps and assisted cough techniques to remove secretions. ${ }^{38}$

\section{Competing interests None declared.}

Provenance and peer review. Commissioned; externally peer reviewed. This paper was reviewed by Martin Turner, Oxford, UK.

(C) Article author(s) (or their employer(s) unless otherwise stated in the text of the article) 2017. All rights reserved. No commercial use is permitted unless otherwise expressly granted.

\section{REFERENCES}

1 Newall AR, Orser R, Hunt M. The control of oral secretions in bulbar ALS/MND. J Neurol Sci 1996;139:43-4.

2 Rudney JD, Ji Z, Larson CJ. The prediction of saliva swallowing frequency in humans from estimates of salivary flow rate and the volume of saliva swallowed. Arch Oral Biol 1995;40:507-12.

3 Stuchell RN, Mandel ID. Salivary gland dysfunction and swallowing disorders. Otolaryngol Clin North Am 1988;21:649-61.

4 Proctor GB. The physiology of salivary secretion. Periodontol 2000 2016;70:11-25.

5 Srivanitchapoom P, Pandey S, Hallett M. Drooling in Parkinson's disease: a review. Parkinsonism Relat Disord 2014;20:1109-18.

6 Marks L, Turner K, O’Sullivan J, et al. Drooling in Parkinson's disease: a novel speech and language therapy intervention. Int $J$ Lang Commun Disord 2001;36:282-7.

7 Nicaretta DH, Rosso AL, Mattos JP, et al. Dysphagia and sialorrhea: the relationship to Parkinson's disease. Arq Gastroenterol 2013;50:42-9.

8 Stone CA, O'Leary N. Systematic review of the effectiveness of botulinum toxin or radiotherapy for sialorrhea in patients with amyotrophic lateral sclerosis. J Pain Symptom Manage 2009;37:246-58.

9 Tahmassebi JF, Curzon ME. Prevalence of drooling in children with cerebral palsy attending special schools. Dev Med Child Neurol 2003;45:613-7.

10 Parkes J, Hill N, Platt MJ, et al. Oromotor dysfunction and communication impairments in children with cerebral palsy: a register study. Dev Med Child Neurol 2010;52:1113-9.

11 Hockstein NG, Samadi DS, Gendron K, et al. Sialorrhea: a management challenge. Am Fam Physician 2004;69:2628-34.

12 Rodrigues B, Nóbrega AC, Sampaio M, et al. Silent saliva aspiration in Parkinson's disease. Mov Disord 2011;26:138-41.

13 Hadjikoutis S, Wiles CM. Respiratory complications related to bulbar dysfunction in motor neuron disease. Acta Neurol Scand 2001;103:207-13.

14 Erasmus CE, Van Hulst K, Van Den Hoogen FJ, et al. Thickened saliva after effective management of drooling with botulinum toxin A. Dev Med Child Neurol 2010;52:e114-8.
15 Vandenberghe N, Vallet AE, Petitjean T, et al. Absence of airway secretion accumulation predicts tolerance of noninvasive ventilation in subjects with amyotrophic lateral sclerosis. Respir Care 2013;58:1424-32.

16 Rashnoo P, Daniel SJ. Drooling quantification: correlation of different techniques. Int J Pediatr Otorhinolaryngol 2015;79:1201-5.

17 Seppi K, Weintraub D, Coelho M, et al. The Movement Disorder Society Evidence-Based Medicine Review Update: treatments for the non-motor symptoms of Parkinson's disease. Mov Disord 2011;26(Suppl 3):S42-80.

18 Perez Lloret S, Pirán Arce G, Rossi M, et al. Validation of a new scale for the evaluation of sialorrhea in patients with Parkinson's disease. Mov Disord 2007;22:107-11.

19 Abdelnour-Mallet M, Tezenas Du Montcel S, Cazzolli PA, et al. Validation of robust tools to measure sialorrhea in amyotrophic lateral sclerosis: a study in a large French cohort. Amyotroph Lateral Scler Frontotemporal Degener 2013;14:302-7.

20 Banfi P, Ticozzi N, Lax A, et al. A review of options for treating sialorrhea in amyotrophic lateral sclerosis. Respir Care 2015;60:446-54.

21 Squires N, Wills A, Rowson J. The management of drooling in adults with neurological conditions. Curr Opin Otolaryngol Head Neck Surg 2012;20:171-6.

22 Moulding MB, Koroluk LD. An intraoral prosthesis to control drooling in a patient with amyotrophic lateral sclerosis. Spec Care Dentist 1991;11:200-2.

23 Chaléat-Valayer E, Porte M, Buchet-Poyau K, et al. Management of drooling in children with cerebral palsy: a French survey. Eur J Paediatr Neurol 2016;20:524-31.

24 Mintzer J, Burns A. Anticholinergic side-effects of drugs in elderly people. J R Soc Med 2000;93:457-62.

25 Prommer E. Anticholinergics in palliative medicine: an update. Am J Hosp Palliat Care 2013;30:490-8.

26 Hobson EV, McGeachan A, Al-Chalabi A, et al. Management of sialorrhoea in motor neuron disease: a survey of current UK practice. Amyotroph Lateral Scler Frontotemporal Degener 2013;14:521-7.

27 Miller RG, Jackson CE, Kasarskis EJ, et al. Practice parameter update: the care of the patient with amyotrophic lateral sclerosis: multidisciplinary care, symptom management, and cognitive/behavioral impairment (an evidence-based review): report of the Quality Standards Subcommittee of the American Academy of Neurology. Neurology 2009;73:1227-33.

28 Mato A, Limeres J, Tomás I, et al. Management of drooling in disabled patients with scopolamine patches. $\mathrm{Br} J$ Clin Pharmacol 2010;69:684-8.

29 Perry EK, Kilford L, Lees AJ, et al. Increased Alzheimer pathology in Parkinson's disease related to antimuscarinic drugs. Ann Neurol 2003;54:235-8.

30 Zeller RS, Davidson J, Lee HM, et al. Safety and efficacy of glycopyrrolate oral solution for management of pathologic drooling in pediatric patients with cerebral palsy and other neurologic conditions. Ther Clin Risk Manag 2012;8:25-32.

31 Foran PG, Mohammed N, Lisk GO, et al. Evaluation of the therapeutic usefulness of botulinum neurotoxin B, C1, E, and F compared with the long lasting type A. Basis for distinct durations of inhibition of exocytosis in central neurons. J Biol Chem 2003;278:1363-71. 
$32 \mathrm{Xu} \mathrm{H}$, Shan XF, Cong X, et al. Pre- and post-synaptic effects of botulinum toxin A on submandibular glands. J Dent Res 2015;94:1454-62.

33 Petracca M, Guidubaldi A, Ricciardi L, et al. Botulinum toxin A and $\mathrm{B}$ in sialorrhea: long-term data and literature overview. Toxicon 2015;107:129-40.

34 Hawkey NM, Zaorsky NG, Galloway TJ. The role of radiation therapy in the management of sialorrhea: a systematic review. Laryngoscope 2016;126:80-5.

35 Kasarskis E, Vanderpool K, St Clair W. C9 treatment of medically refractory sialorrhoea with electron beam radiotherapy (EBRT) to the parotid [Abstract]. Amyotroph Lateral Scler Front Degener 2015;16:6.

36 Reed J, Mans CK, Brietzke SE. Surgical management of drooling: a meta-analysis. Arch Otolaryngol Head Neck Surg 2009;135:924-31.

37 Khan WU, Islam A, Fu A, et al. Four-duct ligation for the treatment of sialorrhea in children. JAMA Otolaryngol Head Neck Surg 2016;142:278-83.

38 Andersen PM, Abrahams S, Borasio GD, et al; EFNS Task Force on Diagnosis and Management of Amyotrophic Lateral Sclerosis. EFNS guidelines on the clinical management of amyotrophic lateral sclerosis (MALS)-revised report of an EFNS Task Force. Eur J Neurol 2012;19:360-75.

39 Arbouw ME, Movig KL, Koopmann M, et al. Glycopyrrolate for sialorrhea in Parkinson disease: a randomized, double-blind, crossover trial. Neurology 2010;74:1203-7.

40 Eiland LS. Glycopyrrolate for chronic drooling in children. Clin Ther 2012;34:735-42.

41 Garnock-Jones KP. Glycopyrrolate oral solution: for chronic, severe drooling in pediatric patients with neurologic conditions. Paediatr Drugs 2012;14:263-9.

42 Sinha S, Simlai J, Praharaj SK. Very low dose amitriptyline for clozapine-associated sialorrhea. Curr Drug Saf 2016;11:262-3.
43 Hyson HC, Johnson AM, Jog MS. Sublingual atropine for sialorrhea secondary to parkinsonism: a pilot study. Mov Disord 2002;17:1318-20.

44 Norderyd J, Graf J, Marcusson A, et al. Sublingual administration of atropine eyedrops in children with excessive drooling - a pilot study. Int J Paediatr Dent2017;27:22-9.

45 Bentivoglio AR, Del Grande A, Petracca M, et al. Clinical differences between botulinum neurotoxin type A and B. Toxicon 2015; 107:77-84.

46 Dressler D, Bigalke H. Botulinum toxin type B de novo therapy of cervical dystonia: frequency of antibody induced therapy failure. J Neurol 2005;252:904-7.

47 Dressler D, Hallett M. Immunological aspects of Botox, Dysport and Myobloc/NeuroBloc. Eur J Neurol 2006;13(Suppl 1):11-15.

48 Møller E, Daugaard D, Holm O, et al. Repeated treatments of drooling with botulinum toxin B in neurology. Acta Neurol Scand 2015;131:51-7.

49 Vashishta R, Nguyen SA, White DR, et al. Botulinum toxin for the treatment of sialorrhea: a meta-analysis. Otolaryngol Head Neck Surg 2013;148:191-6.

50 Faria J, Harb J, Hilton A, et al. Salivary botulinum toxin injection may reduce aspiration pneumonia in neurologically impaired children. Int J Pediatr Otorhinolaryngol 2015;79:2124-8.

51 Intiso D, Basciani M. Botulinum toxin use in neurorehabilitation to treat obstetrical plexus palsy and sialorrhea following neurological diseases: a review. NeuroRehabilitation 2012;31:117-29.

52 Layton TB. An unusual complication of Botox treatment for sialorrhoea. Int J Surg Case Rep 2014;5:1072-3.

53 Barbero P, Busso M, Tinivella M, et al. Long-term follow-up of ultrasound-guided botulinum toxin-A injections for sialorrhea in neurological dysphagia. J Neurol 2015;262:2662-7. 